\title{
Martí de Riquer Morera (17-IX-2013)
}

El millor que es pot dir d'aquest gran humanista català, traspassat a la mateixa Barcelona que el va veure néixer el 1914 ara farà un segle, és que d'una manera sàvia i entenedora ens va ajudar a estimar el bo i millor de les literatures romàniques medievals. Vertader savi i vertader mestre, la seva llarga existència fou una constant interacció entre l'estudi subtil, quasi detectivesc, dels textos literaris més variats i la generosa divulgació dels sabers acumulats.

Educat en la Catalunya oberta i liberal d'entreguerres, en el sí d'una família de noble llinatge, la llarga peripècia de la qual va deixar magistralment documentada en Quinze generacions d'una família catalana (Barcelona, Quaderns Crema, 1979 i 1998/2), el seu primer llibre, L'humanisme català (1934), aviat seguit d'edicions de l' Scipió i Aníbal i De Providentia i de les versions castellanes d'Antoni Canals, la poesia de Jordi de Sant Jordi, de Pere Torroella i d'Andreu Febrer, revelà la precocitat de la seva vocació erudita, sorgida del diàleg directe amb els clàssics catalans i grecollatins i amb els millors mestres d'aquell moment brillant de la cultura catalana. Una etapa val a dir que brutalment malbaratada per una guerra incivil que el jove Riquer va viure com una odissea personal.

Incorporat, el 1942, a una universitat que hom havia «expurgat» de soca-rel d'ensomnis i «males llavors» catalanistes, el nomenament com a professor encarregat i adjunt (1947-50), i més tard, a partir de 1950 com a catedràtic de Literatures romàniques, va determinar la seva vasta carrera (tancada el 1990 com a professor emèrit), especialment centrada en les literatures medievals hispàniques, occitana i francesa. Com que la tradició poètica catalana medieval pren fonament en la tradició trobadoresca, el jove docent, resseguint les petjades de Milà i Fontanals va cercar i trobar la manera d'encabir-la en el restringit programa oficial, enllestint edicions de Bernat de Ventadorn ( 1940), Cerverí de Girona (1945 i 1947) i de Guilhem de Berguedà (1971, i reed.); o la justament famosa La lírica de los trovadors (1948), que arribà a ser la més completa antologia dels trobadors: Los trobadores (1975, 3 vls., amb reed.). Amb el suport de docents com Francesc Noy i Gabriel Oliver, va convertir el Seminari de Romàniques barceloní en un dels millors centres europeus.

D'altra banda, com bé proven treballs de l'abast de la seva tesi doctoral sobre les traduccions castellanes d'Ausiàs March (1945), Riquer va dedicar-se a crear ponts entre la cultura catalana, aleshores estigmatitzada i perseguida, $i$ alguns dels més prestigiosos representants de la cultura castellana «triomfant», com ara Garcilaso, incidint en la remarcable influencia que autors catalans, com l'oblidat Joan Boscà (1945), van exercir sobre els castellans, i en el determinant paper cultural de la Corona d'Aragó com a porta d'entrada de les modes renaixentistes.

Establir ponts, demostrant els vincles lingüístics i culturals d'una constant interdependència, vet ací un dels factors essencials de la seva tasca d'historiador de la cultura romànica medieval. Perquè, de la mateixa manera 
que els poetes medievals catalans no eren comprensibles sense els trobadors, tampoc, ben mirat, ho era el mateix Petrarca. I si, a tall d'exemple, en la dicció garcilasiana era ben precisa la influència del valencianíssim Ausiàs, o d'una manera de versificar importada d'Itàlia a través del barceloní Boscà, tampoc no resultava entenedora la grandesa èpica del Cantar del Mio Cid des de la ignorància de l'èpica francesa, ni convenia acostar-se al Quijote sense abans haver llegit el Tirant.

I com que Riquer era dels mestres que ensenyen allò que abans han investigat o estan investigant, aconseguia de fer participants els seus estudiants en l'aventura d'aquella recerca permanent. Així, si parlava, posem per cas, d'èpica, era des del prestigi i el coneixement que li proporcionava la gestació d'obres com Los cantares de gesta franceses (1952), - la versió francesa de la qual gaudí del privilegi de ser emprat com a llibre de text en la Sorbonne-, o de les edicions i versions de la Chanson de Roland, del Perceval i les llegendes del Graal, etc., que va fer assequibles a tota classe de lectors. Si, per adduir un altre exemple ben representatiu, explicava Bernat Metge, era tot ubicant-lo en el seu context cultural i biogràfic, exhumant-ne tant les fonts clàssiques com la novel-lesca peripècia vital en una edició crítica de l'obra completa (1959), acompanyada d'una versió castellana que acabara de fer-la abastable i entenedora.

La tan divulgada Història de la Literatura Catalana (B. 1964, 3 vols.), és en aquest sentit, una bella síntesi de la magistral docència riqueriana, perquè hi trobem resumit el contingut de llibres i pròlegs escampats arreu en nombroses edicions i monografies de primera mà, quasi sempre difícils de superar i sempre plenes d'intuïcions i de suggerències per a futures recerques.

Igualment paradigmàtic resulta el capítol de la $H L C$ dedicat a la gran novel-la valenciana Tirant lo Blanc. A l'hora d'estudiar i fer-nos reviure les tan humanes aventures del cavaller bretó, el cavaller Martí de Riquer va donar especial prova de la seva extraordinària vigoria i entusiasme intel-lectuals. Perquè al temps que publicava les seves ben conegudes edicions tirantianes anava bastint tota una atapeïda xarxa d'estudis complementaris sobre el fet mateix de la vida cavalleresca $(1965,1970)$, els cavallers errants $(1967,1984,1999)$, les armes medievals (L'arnès del cavaller, 1968) i la mentalitat i complexa casuística de les lletres de batalla (1963-68), sense deixar de banda l'heràldica castellana i catalana $(1943,1986)$ o els castells catalans. Fou a partir d'aquesta impressionant recerca polivalent de la realitat sociohistòrica peninsular de la cavalleria, que Riquer va perfilar la seva visió positivista del gran text literari de Joanot Martorell. Tanmateix, i com succeí en molts d'altres casos, l'excel-lent síntesi plasmada en la $H L C$, estava destinada a ser superada pel mateix Riquer, en unes encara més completes aproximacions posteriors (1990, 1992).

Ja hem anticipat que per a Riquer la lectura del $T B$ anava associada a la del Quijote. Sembla que ja d'infant, de la mà de la mare, va sentir parlar abans del segon que no del primer, cosa d'altra banda no gens estranya, si tenim en compte la dimensió barcelonina del Quijote (tan ben explicitada pel mateix Riquer en el seu Cervantes en Barcelona, 1989), i també la vocació cervantina de la ciutat comtal, seu d'una de les millors col-leccions cervantines del món. El fet innega- 
ble és que Riquer, ara Don Martín, ultra enllestir edicions ben remarcables de Celestina, Arcipreste de Talavera, Juan de Mena, Lazarillo de Tormes, Luís de León, la Vida es Sueño, i de l'Amadís, és autor no d'una, sinó de nombroses edicions ben anotades de la gran obra cervantina, tant de la genuïna com la d'Avellaneda, i d'una Aproximación al Quijote i un guardonat Para leer a Cervantes (2003), que s'han demostrat tan útils i entenedors com els dedicats al Tirant.

És doncs del tot indiscutible que en cadascun dels tres àmbits que hem resumit de manera massa concisa, la tasca acadèmica de Martí de Riquer, de Catalunya estant, va assolir un altíssim nivell d'excel-lència. A més de la docència i la direcció de nombroses tesis doctorals, una breu etapa com a vicerector (1965) i de docent-fundador de la Universitat Autònoma (1970-76), cal destacar la seva importantíssima aportació a la reconstrucció i bona marxa de l'Acadèmia de Bones Lletres de Barcelona. Val a dir que aquesta dedicació, que li valgué l'homenatge de dues belles miscel-lànies d'estudis universitaris (Symposium i Studia, 1986, 1986-88), no sempre fou reconeguda amb igual consistència, i que ho fou més i millor fóra de Catalunya e « incluso más allá de nuestras fronteras», en paraules del rei d'Espanya, que es confessava deixeble seu. Don Martí, va ser, en efecte, tutor del príncep Juan Carlos (1960), que més tard l'anomenaria «senador real». Fou també membre de la «Real Academia Española» (1965) y «Academia de la Historia», Premi «Menéndez y Pelayo», «Principe de Asturias» (1997) i « Nacional de las Letras» (2000). La república francesa l'honorà incorporant-lo a 1'Institut de France en l'Academie des Inscriptions et Belles Letres, i a l'Academie International d'Héraldique. Els alemanys li concediren el Premi Montaigne 1988 en reconeixement a la seva tasca de romanista, que també li va merèixer ser membre de la British Academy, president honorari de la Societé Rencesvals, i doctor honoris causa de les universitats de Lieja i la Sapienza de Roma.

Ara ningú podrà regatejar-li ja aquesta evidència pòstuma d'una obra ben feta, ni la corona de deixebles que han fet seva, amb pregon agraïment, la responsabilitat inherent a l'herència del seu mestratge exemplar.

Albert Hauf Valls

Deixeble i doctorand de Martí de Riquer. IEC, AVL, catedràtic emèrit de les universitats de València i de Gal·les 